\title{
Estratégia como prática: análise longitudinal por meio de bibliometria e sociometria
}

\author{
Strategy as practice: longitudinal analysis through bibliometrics and sociometry
}

Silvana Anita Walter ${ }^{[a]}$, Tatiana Marceda Bachl ${ }^{[b]}$, Flaviane Barbosa ${ }^{[c]}$

[a] Professora do Programa de Pós-Graduação em Administração (PPGAd) e do Programa de Pós-Graduação em Ciências Contábeis e Administração (PPGCC) da Universidade Regional de Blumenau (FURB), Blumenau (SC), Brasil, E-mail: silvanaanita.walter@gmail.com

[b] Mestranda em Administração pela Universidade Regional de Blumenau (FURB), Blumenau (SC), Brasil, E-mail: tatibach@gmail.com

[c] Graduanda em Nutrição pela Universidade Regional de Blumenau (FURB), Blumenau (SC), Brasil,

E-mail: flaviaanee@gmail.com

\section{Resumo}

Esta pesquisa objetivou analisar a estrutura de relacionamento dos atores sociais envolvidos no desenvolvimento da abordagem de estratégia como prática no Brasil e no exterior no período entre 1996 e 2011. Realizou-se uma pesquisa bibiométrica e sociométrica de 143 artigos do exterior e 64 brasileiros. Verificaramse muitas diferenças entre a amostra brasileira e a estrangeira, tanto no tocante ao número de artigos, quanto às redes de relacionamento entre autores e instituições. Notou-se que a abordagem se destaca, principalmente na Inglaterra, visto que as instituições e autores mais prolíficos e mais citados são desse país. Quanto ao Brasil, não se identificaram autores ou instituições proeminentes, bem como se verificou que a maior parte das instituições está localizada nas regiões Sudeste e Sul. Se comparado a países da Europa, o Brasil tem um longo caminho a percorrer no que se refere à abordagem de estratégia como prática, visto o menor número de artigos publicados, a fragmentação das redes de cooperação e o foco em obras que apresentam a abordagem (em comparação com as obras sobre temas específicos citadas no exterior) e a não citação de autores brasileiros. Essa é uma abordagem emergente e em amadurecimento, de forma que os pesquisadores brasileiros podem valer-se desse momento para difundi-la e aplicá-la. Espera-se que este estudo, ao apresentar lacunas ainda não exploradas nos estudos brasileiros, possa contribuir para o amadurecimento dessa abordagem no Brasil, bem como possa, ao apontar obras fundamentais da abordagem e pesquisadores já atuantes na área, nortear pessoas que desejam integrar a área.

Palavras-chave: Estratégia como prática. Bibliometria. Sociometria. 


\begin{abstract}
This research aims to analyze the relationship structure of the social actors involved in the development of the strategy as practice approach in Brazil and abroad in the 1996 to 2011 period. We conducted a bibliometrics and sociometrics research of 143 foreign and 64 Brazilian studies. There were many differences between the foreign and Brazilian samples, both as of the number of papers as well as the relationship networks among authors and institutions. It was noticed that the approach stands mainly in England, as of the most prolific authors and institutions are in that country. As of Brazil, there were no relevant authors or institutions, as well as it was verified that most of the institutions are located in the South and Southeast regions. If compared to European countries, Brazil has a long way to go related to the strategy as practice approach, due to the small number of published papers, the cooperation network fragmentation and the focus on papers that merely present the approach (compared with papers on specific matters cited abroad) and the lack of citations of Brazilian authors. This is an emergent and developing approach, so the Brazilian researchers can take this opportunity to apply and spread it. This research intends, with the presentation of unexplored gaps in Brazilian studies, to contribute to the development of this approach in Brazil, as well as, presenting mainstream papers and active researchers in the field, guide new researchers willing to get into the area.
\end{abstract}

Keywords: Strategy as practice. Bibliometrics. Sociometry.

\section{Introdução}

Em 1996, foi publicada, no exterior, a primeira nota de leitura sobre uma nova abordagem para a área de estratégia: estratégia como prática (ver WHITTINGTON, 1996). Oito anos depois, a tradução de dois artigos estrangeiros para a língua portuguesa foi publicada em uma revista brasileira (ver WHITTINGTON, 2004; WILSON; JARZABKOWSKI, 2004). Essa perspectiva de estratégia, apesar de recente, deriva de um movimento anterior mais amplo, denominado virada da prática, oriundo, nos anos de 1980, da teoria social (SCHATZKI; CETINA; SAVIGNY, 2001; RECKWITZ, 2002).

Após a publicação, no Brasil, desses artigos estrangeiros a respeito da abordagem de estratégia como prática, pesquisadores brasileiros se interessaram por essa concepção diferenciada de estratégia, o que motivou publicações brasileiras dentro dessa perspectiva. Essas publicações sobre estratégia como prática tem se intensificado no Brasil e no exterior a partir da adesão de novos pesquisadores, bem como da abertura de veículos de publicação (eventos e periódicos) de estudos a esse respeito.

Assim, dezesseis anos após a divulgação dessa abordagem no exterior e oito anos no Brasil, é possível levantar alguns questionamentos a respeito de como a produção acadêmica sob essa perspectiva vem sendo desenvolvida. Nesse contexto, considera-se que analisar o campo de conhecimento em estratégia como prática pode fornecer indícios relevantes sobre o desenvolvimento dessa nova perspectiva em estratégia, assim como é possível comparar seu amadurecimento no Brasil, diante de sua entrada posterior em relação à produção estrangeira.

A partir do exposto, desenvolveu-se a presente investigação, que teve por objetivo analisar a estrutura de relacionamento dos atores sociais envolvidos no desenvolvimento da abordagem de estratégia como prática no Brasil e no exterior no período entre 1996 e 2011. Tem-se assim, como pergunta de pesquisa: Qual a estrutura social de relacionamento de autores e de instituições envolvidos no desenvolvimento da abordagem de estratégia como prática no Brasil e no exterior no período entre 1996 e 2011?

Para atingir esse objetivo, optou-se pelo desenvolvimento de uma pesquisa bibiométrica e sociométrica. Como indica Araújo (2006), as pesquisas bibliométricas procuram identificar as principais características das produções científicas de uma área, como temas de estudo e lacunas existentes. A sociometria, de forma complementar, verifica os autores de destaque e as relações de coautoria entre eles (WALTER et al., 2010).

Este artigo, no qual se apresenta a pesquisa realizada, encontra-se organizado em mais quatro seções, além desta introdução: na segunda, apresenta-se a revisão de literatura referente aos principais pressupostos da abordagem de estratégia como prática e às metodologias de bibliometria e sociometria; na terceira, descrevem-se os procedimentos 
metodológicos adotados; na quarta, apresentam-se os resultados encontrados; e, na quinta, tecem-se as considerações finais do estudo.

\section{Base Teórica}

Nesta seção apresenta-se a base teórico-empírica empregada, destacando a abordagem teórica que é objeto de estudo, a estratégia como prática, bem como os métodos de bibliometria e sociometria.

\section{Estratégia como Prática}

Como se destacou, a estratégia como prática é uma abordagem teórica da área de estratégia, que surgiu na década de 1990 (WHITTINGTON, 1996). Essa abordagem procura ampliar o foco de concentração na organização para incluir, também, os estrategistas, ou seja, as pessoas que, por meio de interação, formam as estratégias empregadas pelas organizações (WHITTINGTON, 1996, 2003, 2006; JOHNSON et al., 2007).

De tal forma, sob a perspectiva de estratégia como prática, a estratégia é considerada uma prática social por meio da qual os estrategistas atuam e com a qual interagem (WHITTINGTON, 1996), ou seja, uma atividade organizacional que as pessoas fazem (WHITTINGTON, 2006) por meio da interação entre os envolvidos (JOHNSON et al., 2007). Assim, essa abordagem procura descobrir como as pessoas realizam seu trabalho dentro das organizações, preocupando-se com a efetividade do desempenho dos estrategistas, a qual influencia indiretamente o desempenho da organização como um todo (WHITTINGTON, 2003).

Para a abordagem de estratégia como prática, alguns conceitos são essenciais, pois fundamentam seus pressupostos. Entre esses conceitos, destacam-se o de prática estratégica e o de strategizing. De forma genérica, a prática, segundo Whittington (2006), recorre a rotinas compartilhadas de comportamento que guiam as ações das pessoas, incluindo tradições, normas, maneiras de pensar e atitudes em sentido amplo. Para Jarzabkowski, Balogun e Seidl (2007, p. 11), há as práticas "cognitivas, comportamentais, procedimentais, discursivas, motivacionais e físicas", as quais podem ser combinadas e adaptadas.
Em seu sentido mais específico, essas práticas são consideradas estratégicas à medida que acarretam consequências para os resultados estratégicos, para as direções, para a sobrevivência e para a vantagem competitiva da organização (JOHNSON; MELIN; WHITTINGTON, 2003), mesmo que essas consequências não tenham sido planejadas e articuladas formalmente com a estratégia (JARZABKOWSKI; BALOGUN; SEIDL, 2007).

Whittington (2003) aponta que a noção de prática estratégica implica focar a atenção no trabalho realizado pelas pessoas que se encontram dentro dos processos organizacionais, ou seja, na atividade real das pessoas na formação das estratégias. Isso porque, como destaca Whittington (1996), a prática está relacionada a todos os trabalhos de formação de estratégia, como reuniões, discussões, ferramentas e processamento de números, empregados para sua formulação e implementação de estratégias.

Jarzabkowski (2004) ressalta, ainda, que o conceito de prática estratégica necessita ser considerado no tocante à interação entre diferentes estrategistas, pois, assim, se pode compreender melhor como as práticas são utilizadas na formação de estratégias e como são adaptadas a essas estratégias. A esse respeito, Whittington e Melin (2003) indicam que um elemento central da prática estratégica é o foco na participação ativa das pessoas como praticantes conjuntos de atividades compartilhadas.

A partir do que foi apresentado, nota-se que o conceito de prática estratégica refere-se a scripts de ação que guiam os estrategistas na realização das estratégias e que são compartilhados entre eles (WHITTINGTON, 1996; 2006; JARZABKOWSKI; BALOGUN; SEIDL, 2007). Como tal, a prática estratégica está vinculada à interação entre os estrategistas em diferentes atividades de formação de estratégias (WHITTINGTON; MELIN, 2003; JARZABKOWSKI, 2004). Essas práticas são consideradas estratégicas por favorecerem a sobrevivência e a obtenção de vantagem competitiva pela organização, mesmo que não esteja descrita formalmente (JOHNSON; MELIN; WHITTINGTON, 2003; JARZABKOWSKI; BALOGUN; SEIDL, 2007).

0 conceito de strategizing, por sua vez, relaciona-se com o processo de formação de estratégias e com a maneira como os estrategistas o realizam (WhitTingtoN, 1996). Para Johnson, Melin e Whittington (2003), o strategizing abrange atividades cotidianas da vida da organização, as quais 
se relacionam a resultados estratégicos. Assim, o strategizing inclui as ações, as negociações e as interações entre diferentes atores da organização (JARZABKOWSKI, 2005).

Whittington e Melin (2003) apontam que o strategizing consiste em processos ativos contínuos de estrategistas envolvidos na realização da estratégia. Assim, conforme apontaWhittington (2003), a perspectiva de prática em strategizing preocupa-se em descobrir qual é o trabalho dos estrategistas.

Com o intuito de explicar o strategizing, Jarzabkowski, Balogun e Seidl (2007) desenvolveram um modelo que abrange praxis, práticas e praticantes. A praxis consiste em um "conjunto de atividades locais, socialmente aceitas e estrategicamente importantes para a orientação e a sobrevivência de um grupo, uma organização ou uma indústria", e os praticantes são atores que atuam na construção de práticas estratégicas (JARZABKOWSKI; BALOGUN; SEIDL, 2007, p. 11). Nesse modelo, o strategizing ocorre na interconexão entre prática, praxis e praticantes, envolvendo esses três elementos.

Percebe-se, portanto, que o conceito de strategizing está relacionado ao de prática estratégica, pois ambos se relacionam com a realização da estratégia. Todavia, enquanto a prática estratégia se refere a um script de ação de guia dos estrategistas nesse processo (WHITTINGTON, 2006), o strategizing consiste nas atividades cotidianas empregadas por eles para essa realização (WHITTINGTON, 1996; JOHNSON; MELIN; WHITTINGTON, 2003; WHITTINGTON; MELIN, 2003). Outra semelhança com o conceito de prática estratégica está em o strategizing ocorrer, normalmente, por meio da interação entre os estrategistas (JARZABKOWSKI, 2005).

Diante do apresentado, nota-se que a ênfase da abordagem de estratégia como prática está nos estrategistas das organizações, com destaque para a relação das suas atividades, seus procedimentos compartilhados e suas interações com as estratégias da organização. Essa mudança traz novos horizontes para a pesquisa e para a gestão das organizações, pois as abordagens teóricas anteriores costumavam focar a organização, e não seus integrantes.

\section{Bibliometria e Sociometria}

Neste estudo, empregou-se a bibliometria como método de revisão sistemática de literatura, a qual pode ser definida como estudos que procuram quantificar os processos de comunicação escrita (PRITCHARD, 1969), analisando a produção, a disseminação e o uso da informação em uma área de conhecimento (MACIAS-CHAPULA, 1998). De acordo com Araújo (2006), as pesquisas bibliométricas empregam técnicas estatísticas e matemáticas para identificar características da literatura analisada. Segundo Cooper e Lindsay (1998), a análise bibliométrica possibilita indicar aos novos pesquisadores os temas já tratados em um campo do conhecimento, verificar inconsistências nos estudos já realizados e averiguar lacunas ainda existentes em uma área ou a respeito de um tema.

Nesta pesquisa, empregou-se, também, a sociometria ou análise de redes sociais em complemento à bibliometria. A sociometria analisa atores sociais e suas relações por meio da representação de um conjunto de nós (atores) e seus laços (relações sociais) (GRANOVETTER et al., 1973). No caso de estudos voltados à análise de pesquisas anteriores, os atores podem ser os autores e/ou instituições que publicaram os artigos e os laços são as relações de coautoria nos artigos (WALTER et al., 2010).

Os laços entre atores de uma rede social podem ser de dois tipos: forte ou fraco. 0 primeiro consiste em uma conexão direta entre atores (GRANOVETTER, 1973), na qual as informações a serem compartilhadas tendem a ser as mesmas, com baixa tendência para mudança (BURT, 1992). Esse é o caso de autores que publicam artigos em parceria (WALTER et al., 2010). Já o laço fraco refere-se a contatos indiretos formados por meio de pontes, os quais podem fornecer diferentes fontes de informação e tornam a rede propensa à inovação (GRANOVETTER, 1973). Nesse sentido, no caso das redes de cooperação entre autores, os laços fracos ocorrem quando dois autores não publicaram um artigo juntos, mas ambos realizaram pesquisas diferentes com um terceiro autor comum (WALTER et al., 2010).

Um conjunto de redes possui algumas características, como densidade e centralização. A densidade, de acordo com Marsden (1993), indica quantos atores dessa rede estão conectados uns aos outros, ou seja, quanto maior o número de laços fortes entre os atores da rede, maior sua densidade. A centralização, por sua vez, reflete a centralidade dos atores em suas redes, isto é, o grau de importância do ator na rede no tocante ao agenciamento entre diferentes atores (WASSERMAN; FAUST, 1994). 


\section{Delineamento Metodológico}

Em resposta à problematização apresentada, realizou-se um estudo bibliográfico de caráter bibliométrico e sociométrico.

Foi feita, no período de julho de 2011 a abril de 2012, a coleta de dados por meio da busca de estudos que empregassem os conceitos de estratégia como prática, strategy as practice, strategic practices e strategizing. Realizaram-se as buscas em bases de dados, sites, anais de eventos e periódicos relacionados à área de estudos organizacionais. No âmbito internacional, fizeram-se as buscas nas bases de dados Portal Periódicos Capes (Blackwell, Wilson, Emerald, Sage, Scopus, Science Direct, WileyInterScience e Scielo), EBSCO Multidisciplinar e EBSCOhost, além de no site da comunidade s-a-p e em sites de busca. Assim, localizaram-se artigos nos periódicos: Organization Studies, Journal of Management Studies, Long Range Planning, Strategic Organization, Human Relations, European Management Review, Management Decision, Organization, Competitiveness Review, Journal of Family Business Strategy, Journal of Management Inquiry, Accounting, Organizations and Society, The Journal of Applied Behavioral Science, Research Policy e Journal of Economic Geography. Também se localizaram artigos nos eventos: European Group for Organization Studies (EGOS Colloquium), Academy of Management Proceedings (AOM), Conference at the University of Warwick (Warwick Conference) e Advanced Institute of Management (AIM Research).

No âmbito nacional, foram alvo de análise todos os eventos e periódicos disponíveis no site da Associação Nacional de Pós-Graduação e Pesquisa em Administração (ANAPAD): os anais do Encontro da ANPAD (EnANPAD), Encontro de Estudos em Estratégia (3Es), Encontro de Estudos Organizacionais (EnE0), Encontro de Marketing (EMA), Simpósio da Gestão da Inovação Tecnológica (Simpósio), Encontro de Administração Pública e Governança (EnAPG), Encontro de Gestão de Pessoas e Relações de Trabalho (EnGPR), Encontro de Administração da Informação (EnADI) e Encontro de Ensino e Pesquisa em Administração e Contabilidade (EnEPQ). Igualmente foram alvo de análise os periódicos Revista de Administração Contemporânea (RAC), RAC - Eletrônica e Brazilian Administration Review (BAR).
A opção pelas fontes de dados descritas deve-se à sua importância e representatividade nos contextos brasileiro e internacional no que diz respeito à publicação de estudos organizacionais. Adicionalmente, ressalta-se que as fontes brasileiras selecionadas são classificadas com o conceito "E1" pela Coordenação de Aperfeiçoamento de Pessoal de Nível Superior (CAPES). No tocante aos anais do EnANPAD, esclarece-se que as buscas realizadas se restringiram aos eventos ocorridos a partir de 1997, visto os artigos estarem disponíveis em meio eletrônico a partir dessa edição. As buscas nas demais fontes de dados do Brasil abrangeram os eventos que aconteceram a partir da data de sua criação: 3Es, eventos a partir de 2003; EnE0, a partir de 2000; EMA, a partir de 2004; Simpósio, a partir de 2006; EnAPG, a partir de 2004; EnGPR, no ano de 2007; EnADI, no ano de 2007; e EnEPQ, no ano de 2007; RAC, a partir de 1997; RAC-Eletrônica, a partir de 2007; e BAR, a partir de 2004. Ressalta-se, ainda, que, em 2009, ainda não ocorreram edições desses eventos no Brasil. No tocante aos estudos de bases de dados estrangeiras, elucida-se que o primeiro estudo encontrado foi publicado em 1996, e o mais recente, em 2011.

Frisa-se que, no caso de um estudo publicado em mais de uma fonte, optou-se pela análise da primeira publicação e que, em casos de uma publicação em evento e em periódico, considerou-se a versão veiculada em periódico. Por meio das buscas, localizaram-se 64 estudos brasileiros e 143 estrangeiros, os quais compuseram a amostra. Portanto, teve-se o total de 207 artigos analisados.

Procedeu-se à análise dos dados em separado para artigos publicados no Brasil e no exterior, no tocante: ao número de artigos publicados em cada ano; às redes de cooperação entre autores e entre instituições; às instituições com maior número de laços e mais prolíficas; às obras e autores mais citados nos estudos estrangeiros e brasileiros; e aos indicadores das redes sociais de cooperação. Fizeramse todas essas análises tanto nos estudos brasileiros, quanto nos estrangeiros. Quanto à análise das redes sociais, optou-se pela exploração das redes de coautoria entre autores e instituições, representativas de uma vertente de análise de redes sociais (LIU et al., 2005), por meio do software UCINET $® 6$. Para identificação das temáticas, averiguou-se como ou com qual objetivo os estudos utilizaram SAP, além de que se empregou a técnica de análise de conteúdo - com 
auxílio de uma planilha eletrônica - que, de acordo com Bardin (2002, p. 38), consiste em "um conjunto de técnicas de análise das comunicações que utiliza procedimentos sistemáticos e objetivos de descrição do conteúdo das mensagens". Cabe destacar que se verificou sobreposição de enfoques em alguns estudos, o que fez com que o número de enfoques fosse superior ao número de estudos analisados.

\section{Análise dos Dados e Resultados}

Nota-se, na Tabela 1, que o número de artigos publicados no Brasil é menor do que a metade dos publicados no exterior. Esse resultado relaciona-se tanto à entrada posterior dessa abordagem no país quanto ao fato de estudos estrangeiros abrangerem diferentes países.

Percebe-se, também, que, no exterior, entre a primeira nota de pesquisa publicada em 1996 e a próxima publicação, há um intervalo de quatro anos. No Brasil, um ano após a publicação da tradução de dois artigos estrangeiros, surgiu o primeiro artigo nacional, que é o de Silva (2005), no qual o autor critica a lógica dominante em estratégia e propõe a abordagem de estratégia como prática embasada na teoria da ação como alternativa viável.

Posteriormente, ocorreu uma ampliação no número de artigos nacionais, com seu auge em 2009, mantendo um número relativamente constante

Tabela 1 - Comparativo entre o Número de Artigos Publicados no Estrangeiro e no Brasil

\begin{tabular}{l|c|c|c|c|c|c|c|c|c|c|c|c|c|c}
\hline Local & 1996 & $\mathbf{2 0 0 0}$ & $\mathbf{2 0 1 1}$ & $\mathbf{2 0 0 2}$ & $\mathbf{2 0 0 3}$ & $\mathbf{2 0 0 4}$ & $\mathbf{2 0 0 5}$ & $\mathbf{2 0 0 6}$ & $\mathbf{2 0 0 7}$ & $\mathbf{2 0 0 8}$ & $\mathbf{2 0 0 9}$ & $\mathbf{2 0 1 0}$ & $\mathbf{2 0 1 1}$ & Total geral \\
\hline Estrangeiros & 1 & 1 & 2 & 2 & 11 & 9 & 11 & 30 & 31 & 28 & 8 & 5 & 4 & 143 \\
\hline Brasileiros & - & - & - & - & - & 2 & 1 & 6 & 6 & 10 & 15 & 12 & 12 & 64 \\
\hline Total & 1 & 1 & 2 & 2 & 11 & 11 & 12 & 36 & 37 & 38 & 23 & 17 & 16 & 207 \\
\hline
\end{tabular}

Fonte: Dados da pesquisa

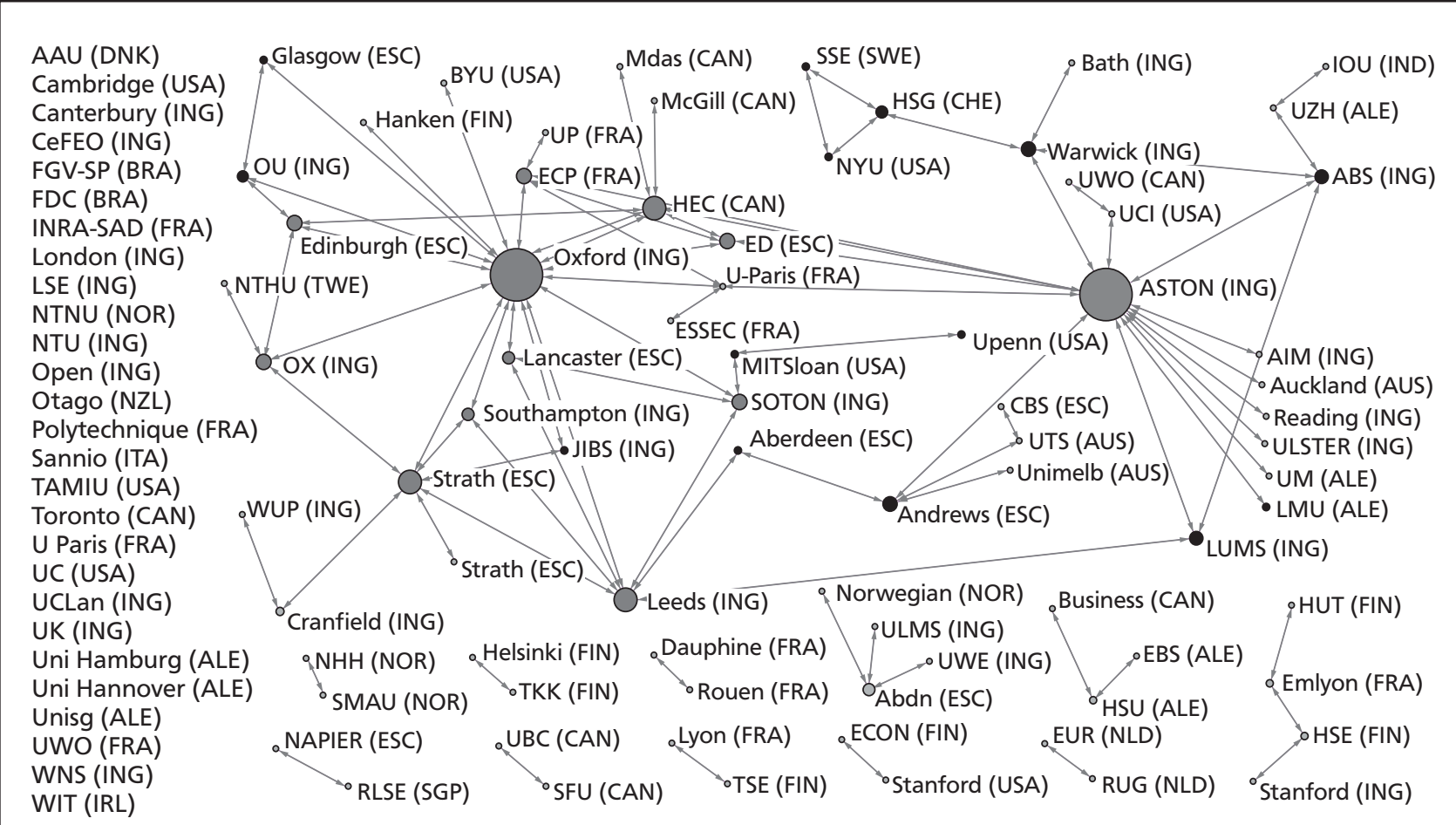

Figura 1 - Redes sociais de cooperação entre instituições dos estudos estrangeiros

Fonte: Dados da pesquisa. 
desde então. No exterior, em contraposição, nota-se uma diminuição no número de publicações a partir de 2009, o que merece acompanhamento para verificação se é uma tendência ou apenas uma mudança de enfoque para veículos de publicação não abrangidos nesta pesquisa, como livros.

Na Figura 1, encontram-se expostas as redes de coautoria entre 104 instituições do exterior.

Visualiza-se, na parte superior da Figura 1, uma rede ampla envolvendo 50 instituições, na qual se destacam duas instituições centrais, ambas da Inglaterra: Oxford, que publicou com 15 instituições diferentes, e Aston, que cooperou com 16 instituições diferentes. A centralidade de um ator na rede relaciona-se ao seu grau de importância no tocante ao agenciamento entre diferentes atores (WASSERMAN; FAUST, 1994). Verificam-se, ainda, redes menores, que variam de duas a quatro instituições, bem como 27 instituições (canto esquerdo da figura) que não estabeleceram laços (nós

Tabela 2 - Instituições com maior número de laços e os mais prolíficos das bases de dados estrangeiras

\begin{tabular}{l|c|c|c}
\hline Instituição & Laços & $\%$ & Art. \\
\hline Oxford (ING) & 27 & 12,6 & 27 \\
\hline Aston (ING) & 24 & 11,2 & 28 \\
\hline Strath (ESC) & 9 & 4,2 & 5 \\
\hline Leeds (ING) & 8 & 3,7 & 4 \\
\hline OX (ING) & 7 & 3,3 & 1 \\
\hline ECP (FRA) & 6 & 2,8 & 3 \\
\hline Warwick (ING) & 6 & 2,8 & 5 \\
\hline HEC (CAN) & 6 & 2,8 & 7 \\
\hline Andrews (ESC) & 5 & 2,3 & 5 \\
\hline ABS (ING) & 4 & 1,9 & 3 \\
\hline Edinburgh(ESC) & 4 & 1,9 & 1 \\
\hline
\end{tabular}

\begin{tabular}{l|c|c|c}
\hline Instituição & Laços & $\%$ & Art. \\
\hline JIBS (ING) & 4 & 1,9 & 3 \\
\hline OU (ING) & 4 & 1,9 & 2 \\
\hline SOTON (ING) & 4 & 1,9 & 1 \\
\hline LUMS (ING) & 4 & 1,9 & 4 \\
\hline ED (ESC) & 4 & 1,9 & 1 \\
\hline Abdn (ESC) & 3 & 1,4 & 2 \\
\hline LMU (ALE) & 3 & 1,4 & 2 \\
\hline Lancaster (ESC) & 3 & 1,4 & 1 \\
\hline HSG (CHE) & 3 & 1,4 & 4 \\
\hline Southampton (ING) & 3 & 1,4 & 1 \\
\hline & & & \\
\hline
\end{tabular}

Fonte: Dados da pesquisa

(continua)

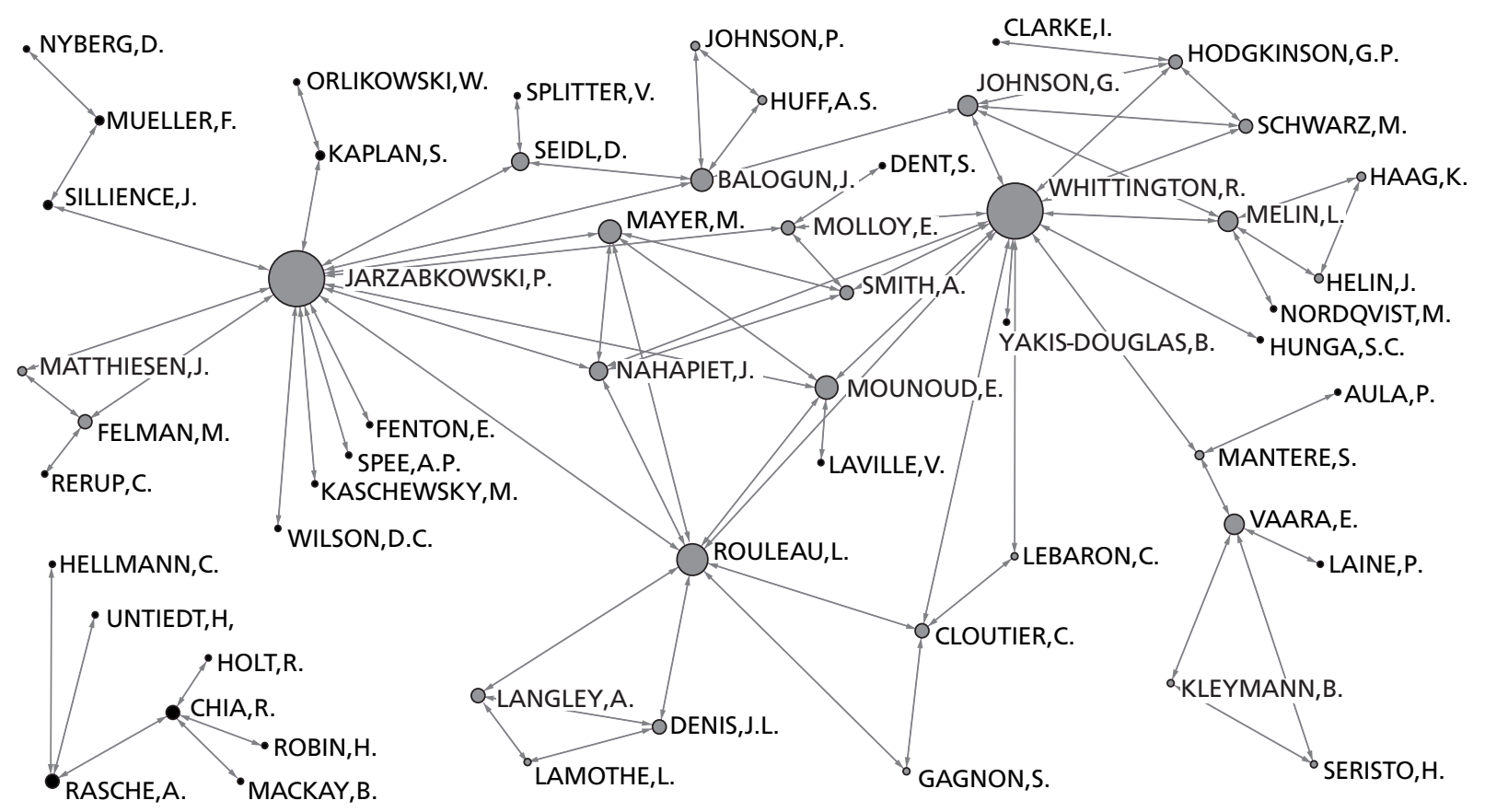

Figura 2 - Redes sociais de cooperação entre autores que publicaram no estrangeiro

Fonte: Dados da pesquisa. 


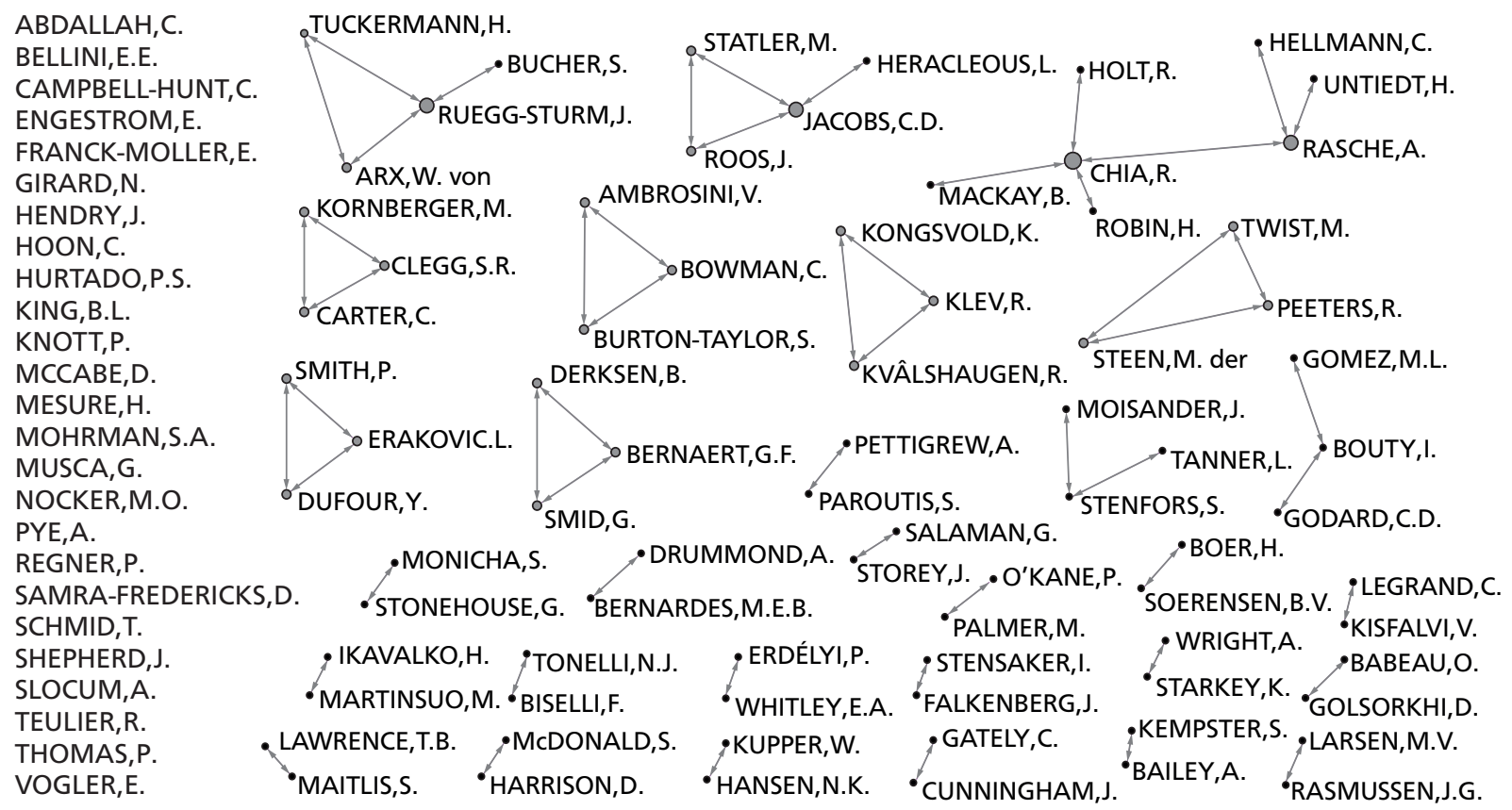

Figura 2 - Redes sociais de cooperação entre autores que publicaram no estrangeiro

Fonte: Dados da pesquisa.

isolados), ou seja, não publicaram em parceria com outras instituições.

Na Tabela 2, expõem-se as instituições que publicaram no exterior com maior número de laços e mais artigos publicados.

Por meio da Tabela 2, percebe-se que Oxford e Aston se destacam não só pelo número de laços e centralidade na rede, como também pelo número de artigos publicados. Pode-se, assim, ressaltar que essas duas instituições são as duas de maior proeminência na área no que se refere à quantidade de publicações, à realização de parcerias e ao agenciamento de informações entre diferentes instituições. É perceptível, igualmente, a predominância de instituições da Europa entre as que publicaram na área, principalmente da Inglaterra, país que se sobressai, também, pelas primeiras publicações na área (de 1996 a 2002).

Na Figura 2, nota-se a existência de uma rede ampla, abrangendo 49 autores, na qual Jarzabkowski e Whittington destacam-se como atores centrais, apresentando, respectivamente, parceria com 15 e 16 diferentes autores. Nessa rede, predomina a ocorrência de laços do tipo fraco. Esse tipo de laço pode fornecer diferentes fontes de informação e torna a rede propensa à inovação (GRANOVETTER, 1973). Observam-se, também, 34 redes menores, abrangendo de dois a sete autores, assim como 25 pesquisadores que não estabeleceram laços, ou seja, publicaram como únicos autores.

Como pode ser percebido na Tabela 3, os autores Jarzabkowski e Whittington também ganham realce no que tange ao número de artigos publicados e ao número de laços estabelecidos, assim como à centralidade já destacada. Esse resultado corrobora o identificado em relação às instituições, visto que esses autores encontram-se vinculados, respectivamente, à Aston e à Oxford. Whittington se destaca, ainda, por ser o autor da primeira nota de pesquisa publicada sobre estratégia como prática em 1996.

Na Tabela 4, exibem-se as obras mais citadas nos artigos publicados no exterior. Além das obras destacadas na tabela, encontraram-se mais 1.489 citadas em menos de 20 artigos.

A obra mais citada entre os estudos do exterior (Tabela 4) foi a de Johnson, Melin e Whittington (2003), na qual os autores propõem uma visão baseada em atividade para a estratégia, analisando o nível micro (processos detalhados e atividades 
Na Tabela 5, observa-se, novamente, a proemi-

cotidianas da organização) e o strategizing. Em segundo lugar, tem-se Whittington (2006), que propõe um modelo de integração entre os níveis macro (externo à organização), meso (organizacional) e micro (estrategistas) por meio da relação entre os conceitos de prática estratégica, praticantes de estratégia e praxis. Na sequência, observa-se Jarzabkowski (2004), que relacionou as teorias sociais de estruturação (GIDDENS, 1984), habitus (BOURDIEU, 1990), formação social (SZTOMPKA, 1991) e comunidades de prática (BROWN; DUGUID, 1991, 2001) com estratégia, apontando a prática estratégica como o ponto de interação entre elas.

Na Tabela 5, exibem-se os autores mais citados nas obras estrangeiras, independentemente das obras. Além dos autores apresentados na tabela encontraram-se mais 1.069 citados em menos de 30 artigos. nência de Whittington e Jarzabkowski dentro da abordagem de estratégia como prática. Assim, diante dos resultados apresentados, tem-se que esses dois autores podem ser tidos como os dois principais expoentes da abordagem analisada.

Na Tabela 6, apresentam-se os temas mais estudados no exterior.

Como se verifica na Tabela 6, o tema mais estudado no exterior é strategizing, o qual está diretamente relacionado à abordagem de estratégia como prática, pois se relaciona com o processo de formação de estratégias e à maneira como os estrategistas o realizam (WHITTINGTON, 1996).

Além dos temas apresentados na Tabela 6, identificaram-se, em três artigos: reuniões e episódios de praxis; conversas estratégicas para

Tabela 3 - Autores com maior número de laços e os mais prolíficos das bases de dados estrangeiras

\begin{tabular}{l|c|c|c}
\hline Instituição & Laços & $\%$ & Art. \\
\hline JARZABKOWSKI, Paula & 32 & 9,2 & 28 \\
\hline WHITTINGTON, Richard & 29 & 8,3 & 25 \\
\hline ROULEAU, Linda & 11 & 3,2 & 5 \\
\hline MAYER, Michael & 11 & 3,2 & 3 \\
\hline JOHNSON, Gerry & 9 & 2,6 & 5 \\
\hline HODGKINSON, Gerard P. & 7 & 2,0 & 2 \\
\hline MOUNOUD, Eléonore & 7 & 2,0 & 3 \\
\hline MOLLOY, Eamonn & 7 & 2,0 & 3 \\
\hline DENIS, Jean L. & 6 & 1,7 & 2 \\
\hline SMITH, Anne & 6 & 1,7 & 2 \\
\hline SEIDL, David & 6 & 1,7 & 5 \\
\hline SCHWARZ, Mirela & 6 & 1,7 & 1 \\
\hline
\end{tabular}

\begin{tabular}{l|c|c|c}
\hline Instituição & Laços & $\%$ & Art. \\
\hline LANGLEY, Ann & 6 & 1,7 & 2 \\
\hline BALOGUN, Julia & 6 & 1,7 & 4 \\
\hline MATTHIESEN, Jane & 5 & 1,4 & 3 \\
\hline MELIN, Leif & 5 & 1,4 & 4 \\
\hline SPEE, Andreas P. & 5 & 1,4 & 4 \\
\hline CHIA, Robert & 5 & 1,4 & 5 \\
\hline NAHAPIET, Janine & 5 & 1,4 & 1 \\
\hline RASCHE, Andreas & 4 & 1,1 & 4 \\
\hline CLOUTIER,Charlotte & 4 & 1,1 & 3 \\
\hline MANTERE, Saku & 4 & 1,1 & 5 \\
\hline VAARA, Eero & 4 & 1,1 & 3 \\
\hline \multicolumn{2}{|l|}{}
\end{tabular}

Fonte: Dados da pesquisa

Tabela 4 - Obras mais citadas nos estudos das bases de dados estrangeiras que abordam SAP

\begin{tabular}{l|c}
\hline Obras & Citações \\
\hline Johnson, Melin e Whittington (2003) & 124 \\
\hline Whittington (2006a) & 90 \\
\hline Jarzabkowski (2004) & 80 \\
\hline Jarzabkowski (2005a) & 75 \\
\hline Jarzabkowski, Balogun e Seidl (2007) & 74 \\
\hline Whittington (2003) & 74 \\
\hline Whittington (1996) & 57 \\
\hline Hendry (2000) & 46 \\
\hline Giddens (1984) & 43 \\
\hline Johnson, Langley, Melin e & 41 \\
Whittington (2007) & 35 \\
\hline Hendry e Seidl (2003) & 35 \\
\hline Jarzabkowski (2003) & 30 \\
\hline Balogun e Johnson (2004) & \\
\hline
\end{tabular}

\begin{tabular}{l|c}
\hline Obras & Citações \\
\hline Rouleau (2005) & 30 \\
\hline Samra-Fredericks (2003) & 29 \\
\hline Whittington (2002a) & 28 \\
\hline Whittington, Jarzabkowski, Mayer, & 27 \\
Mounoud, Nahapiet e Rouleau (2003) & 26 \\
\hline Regnér (2003) & 25 \\
\hline Orlikowski (2000) & 23 \\
\hline Knights e Morgan (1991) & 23 \\
\hline Mintzberg (1994) & 22 \\
\hline Jarzabkowski e Wilson (2002) & 21 \\
\hline Balogun e Johnson (2005) & 21 \\
\hline Pettigrew (1992) & 20 \\
\hline Barry e Elmes (1997) & 20 \\
\hline Mantere (2005) & 20 \\
\hline
\end{tabular}

Fonte: Dados da pesquisa 
Tabela 5 - Autores mais citados nos estudos estrangeiros

\begin{tabular}{l|c}
\hline Autores & Cit. \\
\hline WHITTINGTON, Richard & 585 \\
\hline JARZABKOWSKI, Paula & 452 \\
\hline JOHNSON, Gerry & 297 \\
\hline MELIN, Leif & 188 \\
\hline BALOGUN, Julia & 181 \\
\hline SEIDL, David & 169 \\
\hline PETTIGREW, Andrew & 107 \\
\hline MINTZBERG, Henry & 84 \\
\hline HENDRY, John & 83 \\
\hline LANGLEY, Ann & 75 \\
\hline BROWN,John S. & 70 \\
\hline ROULEAU, Linda & 68 \\
\hline GIDDENS, Anthony & 57 \\
\hline ORLIKOWSKI, Wanda J. & 56 \\
\hline
\end{tabular}

\begin{tabular}{l|c}
\hline Autores & Cit. \\
\hline WILSON, David C. & 55 \\
\hline EISENHARDT, Kathleen M. & 54 \\
\hline WEICK, Karl E. & 50 \\
\hline BLACKLER, Frank & 48 \\
\hline FLOYD, Steven W. & 48 \\
\hline CHIA, Robert & 45 \\
\hline MAYER, Michael & 45 \\
\hline MANTERE, Saku & 44 \\
\hline GRANT, David & 43 \\
\hline TSOUKAS, Hari & 42 \\
\hline SAMRA-FREDERICK, Dalvir & 41 \\
\hline DUTTON, Jane E. & 40 \\
\hline HUFF, Anne S. & 40 \\
\hline WENGER, Etienne & 38 \\
\hline
\end{tabular}

\begin{tabular}{l|c}
\hline Autores & Cit. \\
\hline WHITTINGTON, Richard & 37 \\
\hline JARZABKOWSKI, Paula & 37 \\
\hline JOHNSON, Gerry & 37 \\
\hline MELIN, Leif & 37 \\
\hline BALOGUN, Julia & 36 \\
\hline SEIDL, David & 35 \\
\hline PETTIGREW, Andrew & 35 \\
\hline MINTZBERG, Henry & 34 \\
\hline HENDRY, John & 34 \\
\hline LANGLEY, Ann & 34 \\
\hline BROWN,John S. & 33 \\
\hline ROULEAU, Linda & 31 \\
\hline GIDDENS, Anthony & 30 \\
\hline ORLIKOWSKI, Wanda J. & 30 \\
\hline
\end{tabular}

Fonte: Dados da pesquisa

Tabela 6 - Temas mais estudados nos artigos do exterior

\begin{tabular}{l|c}
\hline Obras & Frequência \\
\hline Strategizing & 21 \\
\hline Estrategistas & 11 \\
\hline Strategizing e organizing & 12 \\
\hline Práticas estratégicas & 10 \\
\hline Emprego da análise do discurso & 7 \\
\hline Implicações da abordagem de estratégia como prática & 6 \\
\hline Uso de metodologias e técnicas na abordagem de estratégia como prática & 6 \\
\hline Uso de ferramentas estratégicas em estratégia como prática & 5 \\
\hline Integração entre SAP e outras teorias para o entendimento da estratégia & 5 \\
\hline Postura crítica e analítica em relação às abordagens baseadas em microatividades & 5 \\
\hline Conceitos de "prática social" & 4 \\
\hline Teoria da atividade como forma de abordar estratégia como prática & 4 \\
\hline Estratégia como prática e teorias da ação (Giddens, Bourdieu, Bhaskar e Martin Heidegger) & \\
\hline
\end{tabular}

Fonte: Dados da pesquisa

compreensão do processo estratégico na estratégia como prática; integração dos níveis micro e macro da estratégia; e micropráticas organizacionais na compreensão da mudança. Em dois artigos, encontraram-se os temas: influências de atores externos nas práticas estratégicas da organização (consultores); inovações estratégicas e criação de novas práticas estratégicas cotidianas; SAP e pequenas empresas; defesa à abordagem (resposta de Richard Whittington e Paula Jarzabkowski); e diferença entre estratégia como prática e estratégia como processo.

Na Figura 3, têm-se as redes de coautoria de 37 instituições que publicaram no Brasil.

Na Figura 3, percebe-se uma rede com 17 instituições, destacando-se como centrais a FUCAPE e a UFMG, que realizaram cooperações com quatro instituições diferentes cada uma. Nota-se que essa rede apresenta densidade mais baixa que a de instituições que publicaram no exterior, o que está relacionado ao menor número de publicações na amostra nacional. Têm-se, ainda, quadro redes com duas ou quatro instituições e 10 instituições que não fizeram laços com outras.

Na Tabela 7, destacam-se o número de laços e de artigos das instituições no Brasil.

Percebe-se, por meio da Tabela 7, que as instituições com maior número de artigos publicados são a PUCPR, a UFPR, a FGV, a UFMG e a FURB. As instituições com maior número de laços, por sua vez, são FUCAPE e UFMG. Percebe-se, assim, a predominância de instituições das regiões Sudeste e 


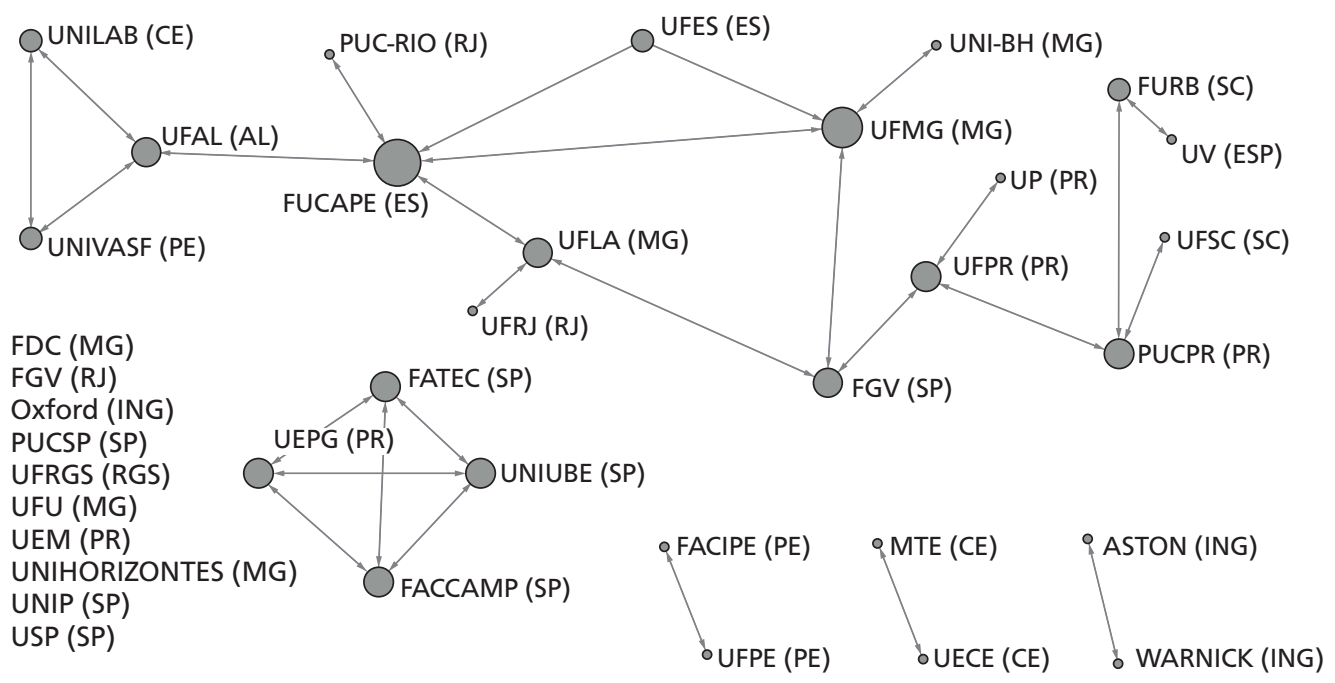

Figura 3 - Redes sociais de cooperação entre instituições dos estudos do Brasil

Fonte: Dados da pesquisa.

Sul, com presença, também, de instituições da região Nordeste. Destaca-se, ainda, que quatro instituições estrangeiras publicaram no Brasil, mas apenas a UV da Espanha estabeleceu parceria com uma instituição brasileira, no caso, a FURB.

Na Figura 4, notam-se as redes de coautoria dos 101 autores que publicaram no Brasil.

A Tabela 4 permite observar que as redes de autores que publicaram no Brasil (no total de 23) são amplamente fragmentadas, visto que a maior rede encontrada envolve apenas nove pesquisadores (canto superior direito). Apesar do reduzido número de autores integrando as redes, verifica-se que aquelas com mais de cinco pesquisadores não apresentam ampla densidade, uma vez que, por exemplo, o autor Alfredo R. L. da Silva, que é central na rede em que se encontra (parte superior central), pois constituiu parceria com seis autores diferentes, estabelece a ponte entre dois grupos de autores que, sem ele, estariam completamente isolados. Na rede do canto superior direito, de forma similar, têm-se Paulo 0. M. Augusto e Clóvis L. Machado-da-Silva estabelecendo ligação fundamental na rede, pois, sem eles, a maioria dos

Tabela 7 - Instituições com maior número de laços e os mais prolíficos das bases de dados do Brasil

\begin{tabular}{l|c|c|c}
\hline Instituição & Laços & $\%$ & Art. \\
\hline PUCPR (PR) & 3 & 5,2 & 12 \\
\hline UFPR (PR) & 2 & 3,4 & 10 \\
\hline FGV (SP) & 3 & 5,2 & 9 \\
\hline UFMG (MG) & 4 & 6,9 & 8 \\
\hline FURB (SC) & 2 & 3,4 & 6 \\
\hline FUCAPE(ES) & 6 & 10,3 & 4 \\
\hline UFLA (MG) & 3 & 5,2 & 4 \\
\hline UFES (ES) & 3 & 5,2 & 3 \\
\hline UFSC (SC) & 2 & 3,4 & 3 \\
\hline UFPE (PE) & 1 & 1,7 & 3 \\
\hline UNIUBE(SP) & 3 & 5,2 & 1 \\
\hline FATEC (SP) & 3 & 5,2 & 1 \\
\hline UEPG (PR) & 3 & 5,2 & 1 \\
\hline
\end{tabular}

\begin{tabular}{l|c|c|c}
\hline Instituição & Laços & $\%$ & Art. \\
\hline FACCAMP (SP) & 3 & 5,2 & 1 \\
\hline UFAL (AL) & 3 & 5,2 & 1 \\
\hline UNIVASF (PE) & 2 & 3,4 & 1 \\
\hline UNILAB (CE) & 2 & 3,4 & 1 \\
\hline MTE (CE) & 1 & 1,7 & 1 \\
\hline PUC-Rio (RJ) & 1 & 1,7 & 1 \\
\hline UFRJ (RJ) & 1 & 1,7 & 1 \\
\hline UECE (CE) & 1 & 1,7 & 1 \\
\hline ASTON (ING) & 1 & 1,7 & 1 \\
\hline UV (ESP) & 1 & 1,7 & 1 \\
\hline UNI-BH (MG) & 1 & 1,7 & 1 \\
\hline FACIPE (PE) & 1 & 1,7 & 1 \\
\hline UP (PR) & 1 & 1,7 & 2 \\
\hline
\end{tabular}

\begin{tabular}{l|c|c|c}
\hline Instituição & Laços & $\%$ & Art. \\
\hline WARNICK (ING) & 1 & 1,7 & 1 \\
\hline Oxford (ING) & 0 & 0 & 1 \\
\hline UFRGS (RS) & 0 & 0 & 1 \\
\hline FDC (MG) & 0 & 0 & 1 \\
\hline UNIP (SP) & 0 & 0 & 1 \\
\hline PUCSP (SP) & 0 & 0 & 1 \\
\hline UNIHORIZONTES & 0 & 0 & 1 \\
(MG) & & & \\
\hline UFU (MG) & 0 & 0 & 1 \\
\hline USP (SP) & 0 & 0 & 1 \\
\hline UEM (PR) & 0 & 0 & 1 \\
\hline FGV (RJ) & 0 & 0 & 1 \\
\hline & & & \\
\hline
\end{tabular}

Fonte: Dados da pesquisa 


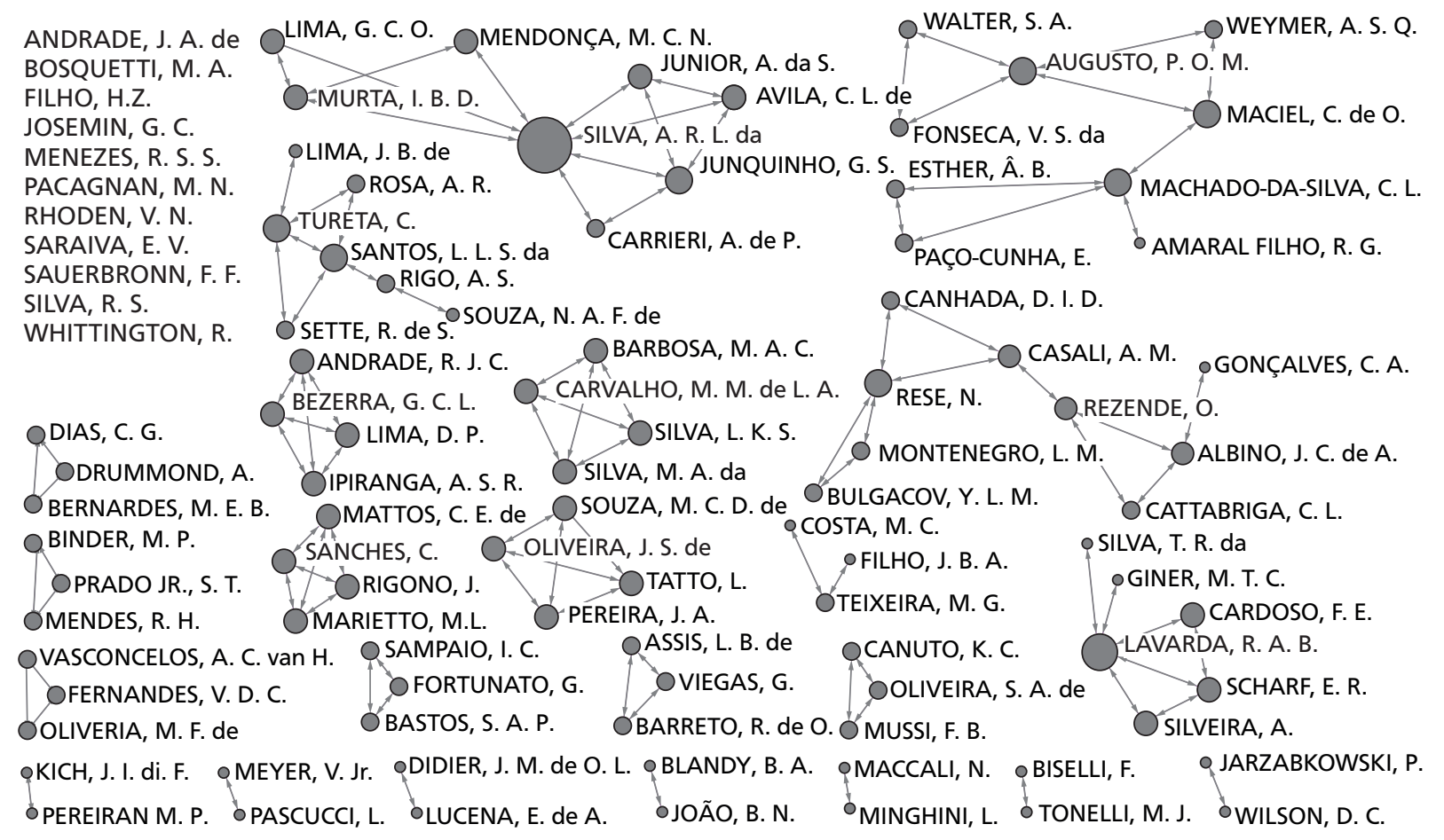

Figura 4 - Redes sociais de cooperação entre autores que publicaram no Brasil

Fonte: Dados da pesquisa.

autores estaria em pequenas redes. Verificam-se, também, 11 autores que não realizaram laços. Essa fragmentação das redes está relacionada ao número restrito de artigos na amostra brasileira.

Na Tabela 8, destacam-se os autores com mais laços e de publicações no Brasil.

Como se observa na Tabela 8, Paulo 0. M. Augusto e Alfredo R. L. da Silva são os autores que apresentam maior número de laços. Esses autores também se apresentaram centrais em suas redes, apesar da fragmentação encontrada. Silvana A. Walter, por outro lado, destaca-se por possuir o maior número de publicações.

As obras mais citadas nos estudos do Brasil podem ser visualizadas na Tabela 9. Além das obras indicadas na tabela, encontraram-se mais 427 citadas em menos de 7 estudos.

A obra mais citada nos artigos publicados no Brasil (Tabela 9) foi a de Jarzabkowski (2005), que ficou em quarta colocação no exterior, e na qual a autora aborda a estratégia como prática como uma abordagem baseada na atividade. Uma das contribuições dessa obra é a categorização da estratégia como prática em três tipos - racionais, discursivas e episódicas -, além de que, não considerando as coletâneas de artigos organizadas em livro, é uma das poucas que abordam, especificamente, estratégia como prática.

Em segunda colocação, no Brasil, têm-se Whittington (1996) e Whittington (2006), sétima e segunda colocadas, respectivamente, no exterior. O texto de Whittington (1996) é a primeira nota de leitura identificada a respeito de estratégia como prática, na qual o autor exibe a abordagem emergente, procurando apresentar seus pressupostos e implicações.

A obra mais citada no exterior - de Johnson, Melin e Whittington (2003) - ficou em nona colocação no Brasil, enquanto a terceira mais citada no exterior, no caso, a de Jarzabkowski (2004), ficou em quinta no Brasil. Percebe-se, ainda, que todas as obras apresentadas na Tabela 9 são de autores estrangeiros, demonstrando que os autores brasileiros não costumam citar trabalhos de seu país, possivelmente pelo fato de existir uma quantidade maior de obras estrangeiras, assim como pela abordagem estar mais amadurecida em outros países. 
Tabela 8 - Autores com maior número de laços e os mais prolíficos das bases de dados do Brasil

\begin{tabular}{l|c|c|c}
\hline Autores & Laços & $\%$ & Art. \\
\hline AUGUSTO, Paulo O. M. & 9 & 3,9 & 5 \\
\hline SILVA, Afredo R. L. da & 8 & 3,4 & 3 \\
\hline LAVARDA, Rosália A.B. & 7 & 3,0 & 5 \\
\hline TURETA, César & 7 & 3,0 & 5 \\
\hline SANTOS, Leonardo L. S. da & 7 & 3,0 & 4 \\
\hline WALTER, Silvana. A. & 6 & 2,6 & 7 \\
\hline JUNQUILHO, Gelson S. & 5 & 2,2 & 2 \\
\hline MACIEL, Cristiano de O. & 4 & 1,7 & 5 \\
\hline RESE, Natália & 4 & 1,7 & 2 \\
\hline MACHADO-DA-SILVA, Clóvis L. & 4 & 1,7 & 2 \\
\hline ROSA, Alexandre R. & 4 & 1,7 & 2 \\
\hline CARDOSO, F. E. & 4 & 1,7 & 1 \\
\hline MURTA, Ivana B. D. & 3 & 1,3 & 1 \\
\hline MARIETTO, Marcio L. & 3 & 1,3 & 1 \\
\hline BEZERRA, George C. L. & 4 & 1,7 & 1 \\
\hline SANCHES, Cida & 3 & 1,3 & 1 \\
\hline MENDONÇA, Milena C. N. & 3 & 1,3 & 1 \\
\hline PEREIRA, Jaiane A. & 3 & 1,3 & 1 \\
\hline AVILA, Cleide L. & 3 & 1,3 & 1 \\
\hline BARBOSA, Milka A. C. & 3 & 1,3 & 1 \\
\hline
\end{tabular}

\begin{tabular}{l|c|c|c}
\hline Autores & Laços & $\%$ & Art. \\
\hline MATTOS, Carlos E. de & 3 & 1,3 & 1 \\
\hline $\begin{array}{l}\text { CARVALHO, Manuella } \\
\text { M. de L. A. }\end{array}$ & 3 & 1,3 & 1 \\
\hline SILVA, Maria A. da & 3 & 1,3 & 1 \\
\hline CASALI, Adriana M. & 3 & 1,3 & 1 \\
\hline IPIRANGA, Ana S. R. & 3 & 1,3 & 1 \\
\hline SILVEIRA, Amélia & 3 & 1,3 & 1 \\
\hline SOUZA, Márcia C. D. de & 3 & 1,3 & 1 \\
\hline MONTENEGRO, Ludmila M. & 3 & 1,3 & 1 \\
\hline ANDRADE, Raphael de J. C. & 3 & 1,3 & 1 \\
\hline BULGACOV, Yára L. M. & 3 & 1,3 & 1 \\
\hline SILVA JUNIOR, Annorda & 3 & 1,3 & 1 \\
\hline SCHARF, Edson R. & 3 & 1,3 & 1 \\
\hline ALBINO, José C. de A & 3 & 1,3 & 2 \\
\hline LIMA, Dorelland P. & 3 & 1,3 & 1 \\
\hline SILVA, Lorenna K. S. & 3 & 1,3 & 1 \\
\hline TATTO, Luiz & 3 & 1,3 & 1 \\
\hline RIGONI, Jociane & 3 & 1,3 & 1 \\
\hline REZENDE, Otávio & 3 & 1,3 & 1 \\
\hline OLIVEIRA, Josiane S. de & 3 & 1,3 & 1 \\
\hline
\end{tabular}

Fonte: Dados da pesquisa

Tabela 9 - Obras mais citadas nos estudos das bases de dados do Brasil que abordam SAP

\begin{tabular}{l|c}
\hline Obras & Citações \\
\hline Jarzabkowski (2005) & 28 \\
\hline Whittington (1996) & 27 \\
\hline Whittington (2006a) & 27 \\
\hline Jarzabkowski, Balogun e Seidl (2007) & 24 \\
\hline Jarzabkowski (2004) & 22 \\
\hline Whittington (2004c) & 22 \\
\hline Jarzabkowski (2003) & 19 \\
\hline Wilson e Jarzabkowski (2004a) & 15 \\
\hline Johnson, Melin e Whittington (2003a) & 13 \\
\hline Balogun, Huff e Johnson (2003) & 12 \\
\hline
\end{tabular}

Fonte: Dados da pesquisa

Na Tabela 10, exibem-se os autores que, independente das obras, foram mais citados nos artigos publicados no Brasil. Além dos autores presentes nessa tabela, encontraram-se mais 358 com citações em menos de sete estudos.

Nota-se, na Tabela 10, que Jarzabbowski e Whittington destacam-se como os mais citados também no Brasil, com a diferença de que a primeira autora aparece como a mais citada no Brasil e a segunda, no exterior. Gerry Johnson, Julia Balogun, Leif Melin e David Seidl igualmente despontam entre os mais citados no Brasil e no exterior. No caso do Brasil, situa-se na quinta colocação o autor Henry Mintzberg, o qual é, muitas vezes, considerado um

\begin{tabular}{l|c}
\hline Obras & Citações \\
\hline Mintzberg, Ahlstrand e Lampel (2000) & 11 \\
\hline Mintzberg e Waters (1985) & 10 \\
\hline Whittington (2002b) & 10 \\
\hline Clegg, Carter e Kornberger (2004) & 9 \\
\hline Johnson, Melin e Whittington (2003b) & 9 \\
\hline Weick (1995) & 8 \\
\hline Whittington (2003) & 8 \\
\hline Whittington, Johnson e Melin (2004) & 8 \\
\hline Mayer, Jarzabkowski, Monoud, Nahapiet, & 7 \\
\hline Whittington (2002a) & 7 \\
\hline
\end{tabular}

autor integrante da abordagem de estratégia como processo, e não de estratégia como prática.

Exibem-se, na Tabela 11, os temas mais estudados nos artigos publicados no Brasil.

Verifica-se, na Tabela 11, que o aspecto mais explorado nos estudos publicados no Brasil é a relação da abordagem de estratégia como prática com outras teorias. Da mesma forma, percebe-se que temas como strategizing e organizing, amplamente explorados no exterior, não apareceram entre os mais frequentes no Brasil.

Apresentam-se, na Tabela 12, as estatísticas aplicadas aos indicadores das redes sociais de cooperação entre os estudos estrangeiros e os do Brasil. 
Tabela 10 - Autores mais citados nos estudos do Brasil

\begin{tabular}{l|c}
\hline Autores & Cit. \\
\hline JARZABKOWSKI, Paula & 169 \\
\hline WHITTINGTON, Richard & 149 \\
\hline JOHNSON, Gerry & 58 \\
\hline BALOGUN, Julia & 42 \\
\hline MINTZBERG, Henry & 42 \\
\hline MELIN, Leif & 37 \\
\hline SEIDL, David & 29 \\
\hline WILSON, David C. & 24 \\
\hline CHIA, Robert & 23 \\
\hline ROULEAU, Linda & 18 \\
\hline PETTIGREW, Andrew & 17 \\
\hline BORDIEU, Pierre & 14 \\
\hline
\end{tabular}

\begin{tabular}{l|c}
\hline Autores & Cit. \\
\hline WEICK, Karl E. & 14 \\
\hline CLEGG, Stewart & 13 \\
\hline LAMPEL, Joseph & 13 \\
\hline MAYER, Michael & 13 \\
\hline AHLSTRAND, Bruce & 12 \\
\hline CARTER, Chris & 12 \\
\hline HUFF, Anne S. & 12 \\
\hline KORNBERGER, Martin & 12 \\
\hline NAHAPIET, Janine & 12 \\
\hline SCHATZKI, Theodore R. & 12 \\
\hline DE CERTEAU, Michel & 11 \\
\hline FLOYD, Steven W. & 11 \\
\hline
\end{tabular}

\begin{tabular}{l|c}
\hline Autores & Cit. \\
\hline ANSOFF, Igor & 10 \\
\hline LANGLEY, Ann & 10 \\
\hline WATERS, James A. & 10 \\
\hline CHILD, John & 9 \\
\hline WOOLDRIDGE, Jeffrey & 9 \\
\hline CHANDLER, Alfred D. & 8 \\
\hline MACKAY, Brad & 8 \\
\hline GIDDENS, Anthony & 7 \\
\hline HENDRY, John & 7 \\
\hline MACHADO-DA-SILVA,Clóvis L. & 7 \\
\hline MOUNOUD, Eléonore & 7 \\
\hline & \\
\hline
\end{tabular}

Fonte: Dados da pesquisa

Tabela 11 - Temas estudados nos artigos do Brasil

\begin{tabular}{l|c}
\hline Temas & Frequência \\
\hline Estratégia como prática aliada ou relacionada a outras teorias & 11 \\
\hline Prática estratégica & 7 \\
\hline Discussões metodológicas e de aplicabilidade de métodos & 6 \\
\hline Análise crítica relacionada à abordagem e a conceitos & 5 \\
\hline Estrategistas internos & 5 \\
\hline Conceito de estratégia & 4 \\
\hline Strategizing & 3 \\
\hline Processo de formação de estratégias e SAP & 3 \\
\hline Estrategistas externos no strategizing (consultores) & \\
\hline Sensemaking - construção de sentidos & 2 \\
\hline Análise da prática social baseada em elementos do discurso & 2 \\
\hline Diferenças de gênero na estratégia como prática & 2 \\
\hline Implicações da estratégia como prática no ensino de administração estratégica & 2 \\
\hline Contribuições das diferentes abordagens da estratégia para a formação de políticas públicas & 1 \\
\hline Construção da estratégia como uma prática social & 1 \\
\hline Mudança & 1 \\
\hline Práxis estratégica e imersão social & 1 \\
\hline Institucionalização da estratégia como prática nos estudos organizacionais & 1 \\
\hline A practice turn e o movimento social da SAP & \\
\hline
\end{tabular}

Fonte: Dados da pesquisa

A partir do índice de centralização das redes para os estudos estrangeiros (4,01\%) e do Brasil $(1,37 \%)$, bem como do grau de centralidade para os estrangeiros (348) e para os do Brasil (232), é possível observar a elevada centralidade da rede, tendo em vista a quantidade de autores diretamente conectados a um ator. Já o índice de heterogeneidade $(2,50 \%$ e $1,53 \%)$ aponta para uma estrutura de relacionamento mais homogênea.

O coeficiente de agrupamento das redes pode ser considerado significativo tanto para os estudos estrangeiros quanto para os do Brasil, uma vez que apresentou, para estudos estrangeiros, um coeficiente observado de 0,873 e esperado de 0,015 e, para os estudos do Brasil, 1,029 para o coeficiente observado e 0,023 para o coeficiente esperado. Os resultados indicam a existência de grupos coesos e característicos de redes do tipo small worlds. 0 coeficiente de agrupamento é caracterizado pela densidade local, por meio de ligações com os mesmos grupos, o que corrobora o estudo de Rossoni e Guarido-Filho (2009), que investigou, em programas de pós-graduação em administração, redes do tipo small worlds. 


\section{Considerações Finais}

Esta pesquisa teve por objetivo analisar a estrutura de relacionamento dos atores sociais envolvidos no desenvolvimento da abordagem de estratégia como prática no Brasil e no exterior no período entre 1996 e 2011. Verificaram-se muitas diferenças entre a amostra brasileira e a estrangeira tanto no tocante ao número de artigos quanto às redes de relacionamento entre autores e instituições.

Verifica-se que a abordagem de estratégia como prática se sobressai, principalmente, na Inglaterra, visto que as instituições e os autores mais prolíficos e mais citados são desse país, destacando-se Jarzabowski, da Universidade de Aston, e Whittington, da Universidade de Oxford. Nesta pesquisa, consideram-se esses autores e suas instituições expoentes da perspectiva de estratégia como prática, visto o número de artigos publicados e de citações de suas obras e a importância desempenhada em suas redes de cooperação.

Em relação ao Brasil, não foi possível identificar autores ou instituições proeminentes, haja vista que a abordagem de estratégia como prática é mais recente no país. Contudo, verificou-se que a maior parte das instituições está localizada nas regiões Sudeste e Sul, não tendo sido encontradas publicações de instituições das regiões Norte, Nordeste ou CentroOeste. Possivelmente, diante da maior concentração de instituições de ensino superior e, principalmente, de programas de pós-graduação stricto sensu nas regiões Sudeste e Sul, tal resultado poderá ser encontrado em diferentes campos de conhecimento, e não apenas em estratégia como prática.

Se comparado a países como Inglaterra e Escócia, que se destacaram na amostra internacional, o Brasil tem um longo caminho a percorrer, visto o menor número de artigos publicados, a fragmentação das redes de cooperação e o foco em obras que apresentam a abordagem (em comparação com as obras sobre temas específicos citadas no exterior) e a não citação de autores brasileiros. Todavia, essa é uma abordagem emergente, de forma que os pesquisadores brasileiros podem valer-se desse momento de desenvolvimento da perspectiva para difundi-la no Brasil, buscando contribuir com seu processo de consolidação.

Como limitação desta pesquisa, aponta-se que o uso de palavras-chave em português e inglês possa ter limitado o número de estudos estrangeiros encontrados. Para futuras pesquisas, sugere-se ampliar as buscas por meio da tradução das palavras-chave a outras línguas, como o espanhol e o francês. Assinalase, ainda, que este estudo indicou a possibilidade de realização de estudos a respeito de temas específicos da abordagem de estratégia como prática pouco explorados no Brasil, como strategizing e organizing. Assim, espera-se que este estudo, ao apresentar lacunas ainda não exploradas nos estudos brasileiros, possa contribuir para o amadurecimento dessa

Tabela 12 - Indicadores das redes sociais de cooperação entre os estudos estrangeiros e os do Brasil

\begin{tabular}{l|l|c}
\hline Obras & Estudos estrangeiros & Estudos do Brasil \\
\hline Índice de centralização da rede & & $1,37 \%$ \\
\hline Grau de centralidade da rede & 348 & 232 \\
\hline Grau de centralidade normalizado & 46,40 & 46,40 \\
\hline Heterogeneidade da rede & $2,50 \%$ & $1,53 \%$ \\
\hline Normalidade da rede & $1,85 \%$ & $0,54 \%$ \\
\hline Número médio de laços da rede (k) & & 2,297 \\
\hline Distância média da rede & & 1,723 \\
\hline Densidade da rede & & 2,297 \\
\hline Coeficiente de agrupamento da rede observado & 0,873 & 1,029 \\
\hline Dados aleatórios & & \\
\hline Coeficiente de agrupamento da rede esperado (k/n) & 0,015 & 0,023 \\
\hline PL: Distância Média Esperada (In(n)/ln(k)) & 5,550 \\
\hline Indicadores & 6,008 & \\
\hline PL taxa (PL real / PL aleatório) & & 0,310 \\
\hline CC taxa (CC real / CC aleatório) & 57,190 & 45,246 \\
\hline Q: Coeficiente Small World (CC taxa/ PL taxa) & 111,488 & 145,733 \\
\hline
\end{tabular}

Fonte: Dados da pesquisa 
abordagem no Brasil, bem como possa, ao apontar obras fundamentais da abordagem e pesquisadores já atuantes na área, nortear pessoas que desejam integrar a área.

\section{Referências}

ARAÚJO, C. A. Bibliometria: evolução histórica e questões atuais. Em Questão, v. 12, n. 1, p. 11-32, jan./jun. 2006.

BARDIN, L. Análise de conteúdo. Lisboa: Edições 70, 2002.

BURT, R. Structural holes: the social structure of competition. Cambridge, MA: Havard University Press, 1992.

COOPER, H. M.; LINDSAY, J. J. Research synthesis and meta-analysis. In: BICKMAN, L.; ROG, D. J. (Eds.). Handbook of applied social research methods. London: Sage Publications, 1998, p. 315-338.

GALASKIEWICZ, J.; WASSERMAN, S. Advances in social network analysis: research in the social and behavioral sciences. London: Sage, 1994.

GRANOVETTER, M. The Strength of Weak Ties. American Journal of Sociology, v. 78, n. 6, 1973, p. 1360-1380.

JARZABKOWSKI, P. Strategy as practice: recursiveness, adaptation, and practices-in-use. Organization Studies, 25, 4, 529-560, London, 2004.

JARZABKOWSKI, P. Strategy as practice: an activity-based approach. London: Sage, 2005.

JARZABKOWSKI, P.; BALOGUN, J.; SEIDL, D. Strategizing: the challenges of a practice perspective. Human Relations, v. 60, n. $5,2007$.

JOHNSON, G.; MELIN, L.; WHITTINGTON, R. Guest editors' introduction - micro strategy and strategizing: towards an activity-based view. Journal of Management Studies, v. 40, n. 1, p. 3-22, jan. 2003.
JOHNSON, G.; LANGLEY, A.; MELIN, L.; WHITTINGTON, $\mathrm{R}$. Introducing the strategy as practice perspective. In: JOHNSON, G.; LANGLEY, A.; MELIN, L.; WHITTINGTON, R. Strategy as practice: research directions and resources. New York: Cambridge, 2007. p. 3-27.

MACIAS-CHAPULA, C. A. O papel da informetria e da cienciometria e sua perspectiva nacional e internacional. Ciência da Informação, v. 27, n. 2, p. 134-140, 1998.

MARSDEN, P. V. The reliability of network density and composition measures. Social Networks, v. 15, n. 4, p. 399421, 1993.

PRITCHARD, A. Statistical bibliography or bibliometrics? Journal of Documentation, v. 25, n. 4, p. 348-349, dec. 1969.

RECKWITZ, A. Toward a theory of social practices: a development in cultural theorizing. European Journal of Social Theory, v. 5, n. 2, p. 243-263, 2002.

ROSSONI, L.; GUARIDO FILHO, E. R. Cooperação entre programas de pós-graduação em administração no Brasil: evidências estruturais em quatro áreas temáticas. Revista de Administração Contemporânea, v. 13, n. 3, p. 366-390, jul./ago. 2009.

SCHATZKI, T. R.; CETINA, K. K.; SAVIGNY, E. V. The practice turn in contemporary theory. Londres: Routledge, 2001.

SILVA, R. S. Revisão e crítica da "lógica dominante" no pensamento estratégico: uma abordagem pela teoria da agência. In: ENCONTRO DE ESTUDOS EM ESTRATÉGIA, 2, 2005, Rio de Janeiro. Anais... Rio de Janeiro: ANPAD, 2005.

WALTER, S. A.; LANZA, B. B. B.; SATO, K. H., SILVA, E. D. da; BACH, T. M. Análise da produção científica de 1997 a 2009 na área de estratégia: produção e continuidade de atores e cooperação entre instituições brasileiras e estrangeiras. In: ENCONTRO DA ASSOCIAÇÃO NACIONAL DOS PROGRAMAS DE PÓS-GRADUAÇÃO EM ADMINISTRAÇÃO, 34, 2010, São Paulo. Anais... Rio de Janeiro: ANPAD, 2010. 
WASSERMAN, S.; FAUST, K. Social network analysis: methods and applications. Cambridge University Press, 1994.

WhitTington, R. Strategy as practice. Long Range Planning, v. 29, n. 5, p. 731-735, October 1996.

WHITTINGTON, R. The work of strategizing and organizing: for a practice perspective. Strategic Organization, v. 1, n. 117, 2003.

WHITTINGTON, R. Estratégia após o modernismo: recuperando a prática. Revista de Administração de Empresas, v. 44, n. 4, 2004.

WHITTINGTON, R. Completing the practice turn in strategy research. Organization Studies, v. 27, n. 5, p. 613-634, 2006.

WHITTINGTON, R.; MELIN, L. The Challenge of Organizing/ Strategizing. In: PETTIGREW, A. M. (Ed.). Innovative forms of organizing: international perspectives. London; Thousand Oaks: Sage Publications, 2003, P. 35-48.

WILSON, D. C.; JARZABKOWSKI, Pa. Pensando e agindo estrategicamente: novos desafios para a análise estratégica. Revista de Administração de Empresas, v. 44, n. 4, 2004.

Recebido: 02/08/2012

Received: 08/02/2012

Aprovado: 27/11/2012

Approved: $11 / 27 / 2012$ 